\title{
Epidemiology of shoulder impingement in upper arm sports events
}

\author{
Y.P.C. Lo1 ${ }^{1}$ SRP, Y.C.S. Hsu ${ }^{2}$, FRCS and K.M. Chan ${ }^{3}$, FRCS \\ ${ }^{1}$ Lecturer in Physiotherapy, Hong Kong Polytechnic, Hong Kong \\ 2 Lecturer in Orthopaedic Surgery and Traumatology, Chinese University, Hong Kong \\ ${ }^{3}$ Reader in Orthopaedic Surgery and Traumatology, Chinese University, Hong Kong
}

\begin{abstract}
An epidemiological survey was conducted to collect data relating to the prevalence and frequency of shoulder pain and other related problems among different athletic groups that demanded vigorous upper arm activities. A questionnaire was administered on site thus ensuring that the response rate was 100 percent. Analysis of results revealed that of the 372 respondents there were 242 male (65.1 percent) and 130 female subjects (34.9 percent), with seven (1.9 percent) above the age of 40,119 (32 percent) between the ages of 25 and 40 , and 246 (66.1 percent) below 25 years of age. A total of 163 athletes (43.8 percent) indicated that they had shoulder problems, 109 (29 percent) suffering pain. Diffuse pain was indicated by 20 respondents (5.4 percent), while localized pain during movement was reported in 89 (23.9 percent). The prevalence of shoulder pain ranked highest among volley ball players $(\mathbf{N}=28)$ followed by swimmers $(\mathbf{N}=22)$, while badminton, basketball and tennis participants were equally affected $(\mathbf{N}=10)$.
\end{abstract}

Keywords: Shoulder injuries, upper arm sports, impingement, epidemiology

The rotator cuff comprises four muscles: the supraspinatus superiorly, the subscapularis anteriorly, and the infraspinatus and teres minor posteriorly. Of these muscles, more problems tend to arise from the supraspinatus since it passes in close proximity to the undersurface of the coraco-acromial ligament, the acromio-clavicular joint and the bony roof formed by the acromion. Impingement of the rotator cuff between the undersurface of the acromion and/or coracro-acromial arch and the greater humeral tuberosity occurs as soon as the upper arm is elevated above shoulder level.

Moseley ${ }^{1}$ and Rothman and Parke ${ }^{2}$ reported that there was a 'critical zone' at the supraspinatus tendon where the vasculature of this structure could be affected during movement. Chronic irritation of this poorly vascularized region may lead to an inflammatory response which in turn may cause tendinitis ${ }^{3}$.

Address for correspondence: Mr Y.P.C. Lo, Physiotherapy Section, Department of Rehabilitation Sciences, Hong Kong Polytechnic, Hung Hom, Hong Kong

(C) 1990 Butterworth-Heinemann Ltd 0306-4179/90/030173-05
With inflammation, there will be swelling and thickening of the rotator cuff and thus the efficient passage of the supraspinatus tendon through the subacromial space will be hampered.

Impingement syndromes in the shoulder are common in individuals using their upper arms at or above shoulder level for prolonged periods $s^{4,5}$. On the other hand, Chard et al. suggested that overuse due to sport usually had a favourable outcome since the specific cause of the problem could be avoided ${ }^{6}$. Shoulder impingement syndrome (SIS) is common, the incidence varying between sports ${ }^{7,8}$.

An extensive epidemiological survey was conducted with the aim of collecting information which might enable athletes and related personnel to prevent SIS.

\section{Materials and methods \\ Design of questionnaire}

The questionnaire was in four parts: (i) demographic data (age, sex, height, weight, hand dominace and occupational background); (ii) sport participation data (event, nature of involvement and frequency); (iii) general performance; and (iv) related shoulder problems.

\section{Pilot study}

A pilot study was carried out among physiotherapy students in the Hong Kong Polytechnic. A total of 48 questions had to be answered by those with shoulder problems and previous injuries. Those without symptoms had to answer 35 questions. The entire questionnaire could be completed in seven to ten minutes.

\section{Survey}

The subjects of this study were limited to competitive and regular recreational athletes who participated in vigorous upper arm organized sporting activities. They had either regular sports commitments in their work (physical education teachers or instructors) or regular training or sports competition (district or college representatives). 
Since SIS was more common in those who had prolonged/repeated upper extremity activities at or above shoulder level, participants in badminton, basketball, gymnastics, squash, swimming, table tennis, tennis, field events and volley ball were approached. The Jubilee Sports Centre (JSC) at Shatin became the main resource centre.

The survey was conducted at the sports field where the athletes were trained and/or had their competitions. The questionnaires were completed on site and returned immediately. The response rate of the questionnaire was 100 percent thanks to excellent co-operation from coaches, trainers and athletes.

\section{Results}

The responses were converted into numerical values and the data were analysed by means of Statistical Package for Social Science, Personal Computer (SPSS/PC).

The age and sex distributions of the 372 respondents is shown in Figure 1, the hand-dominance and sides affected in Figure 2.

With regard to their sports background, 70 respondents (18.8 percent) designated themselves as full time participants. This group included the physical education teachers or instructors, trainers and those who were on scholarship for full-time training. A total of 156 respondents (41.9 percent) were in the elite or competitive athletes' category, mainly representatives from colleges, sports associa-
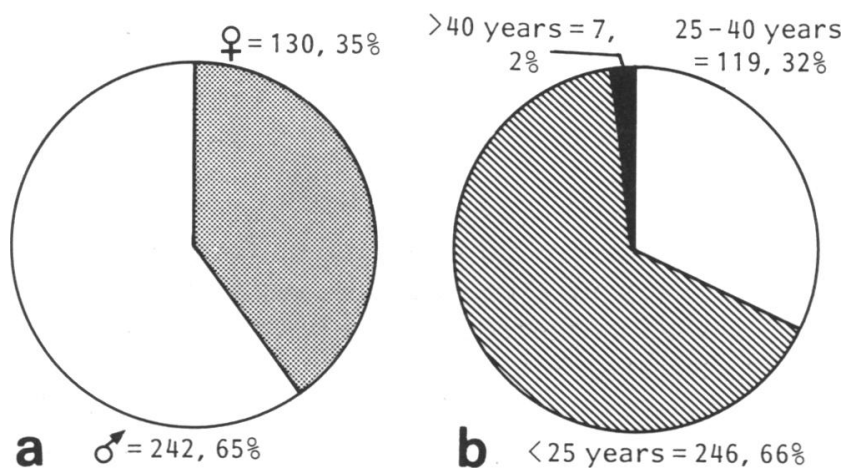

Figure 1. a: Sex distribution; and b: age distribution (years) $(N=372)$

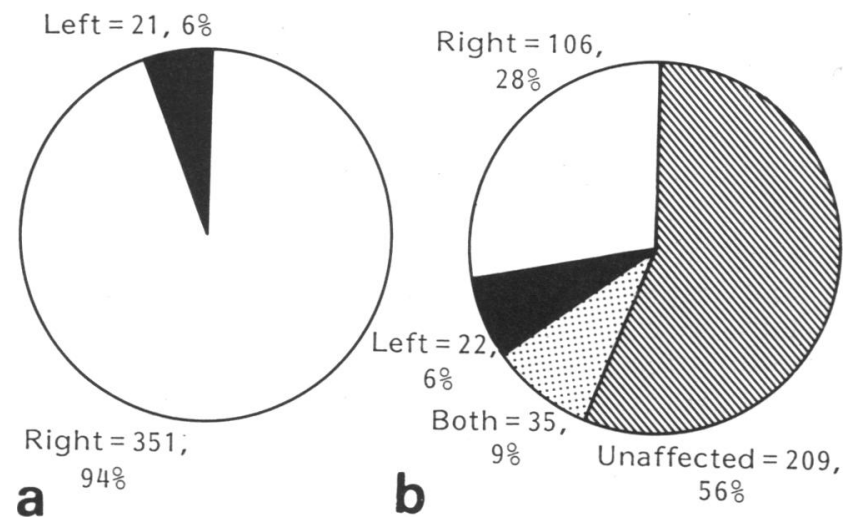

Figure 2. a: Hand dominance and; b: sides affected $(\mathbf{N}=372)$ tions, or Hong Kong team members in certain sports events. The residual 146 (39.2 percent) were recreational athletes taking part in sports events regularly, at least once a week (Figure 3).

The respondents' sports events are shown in Figure 4 and their experience and frequency of participation shown in Figure 5 and in Tables 1 and 2.

Subjects' indications of their arm-level or maximum effort are set out in Figure $6 a$ and in questioning as to which movement they would perform most forcefully, 127 subjects ( 34.1 percent) chose flexion. External rotation was indicated by 54 respondents (14.5 percent) and extension/downward push by 85 (22.8

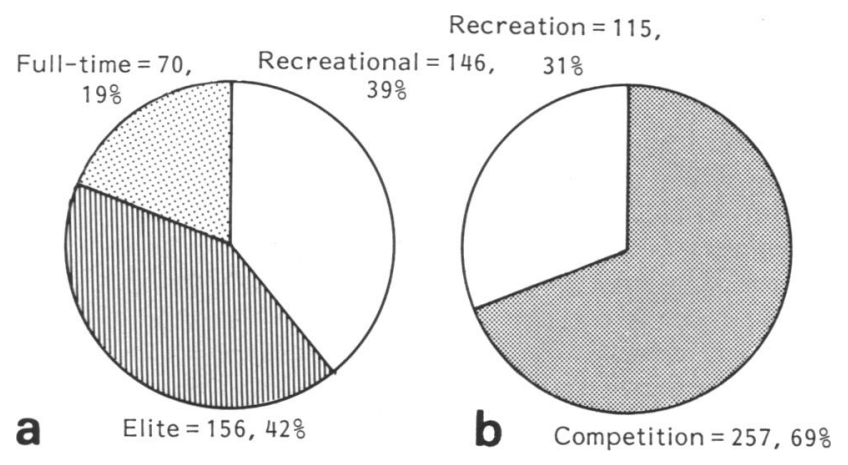

Figure 3. a: Sports background and; b: nature of participation $(N=372)$

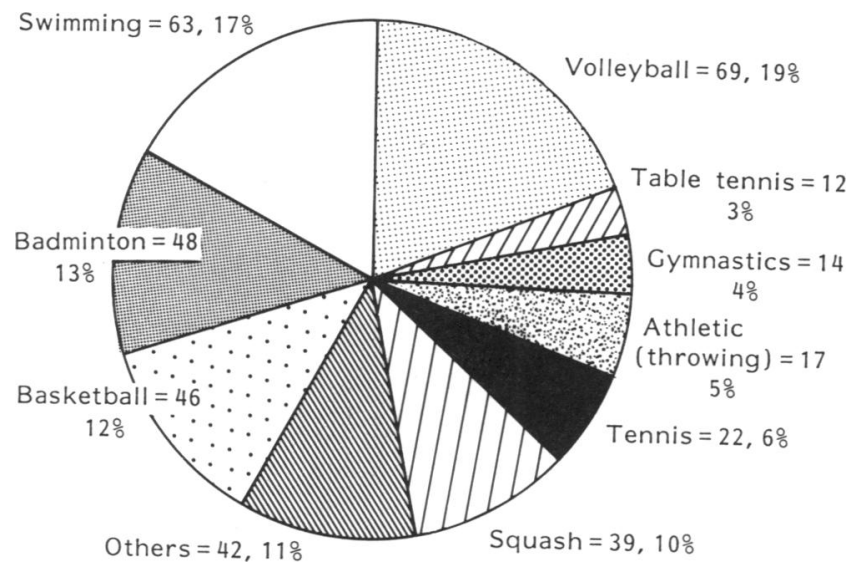

Figure 4. Range of sport events $(N=372)$

Table 1. Frequency of sports participation

\begin{tabular}{lcc}
\hline$<1$ per week & $-34(9.1 \%)$ \\
Once per week & $-57(15.3 \%)$ \\
twice per week & $-83(22.3 \%)$ \\
thrice per week & $-58(15.6 \%)$ \\
four times per week & $-25(6.7 \%)$ \\
$>4$ per week & $-115(30.9 \%)$
\end{tabular}

Table 2. Duration of participation per session

\begin{tabular}{lc}
$<1$ hour & $-31(8.3 \%)$ \\
$1-2$ hours & $-180(48.4 \%)$ \\
$2-3$ hours & $-122(32.8 \%)$ \\
$>3$ hours & $-39(10.5 \%)$ \\
\hline
\end{tabular}


Shoulder impingement in upper arm sports events: Y.P.C. Lo, et al.

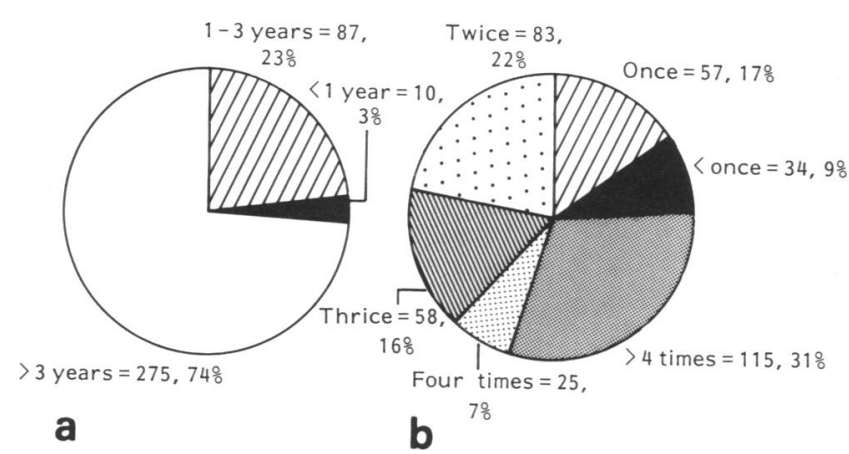

Figure 5. a: History of participation in sport event and; b: frequency of involvement per week $(N=372)$

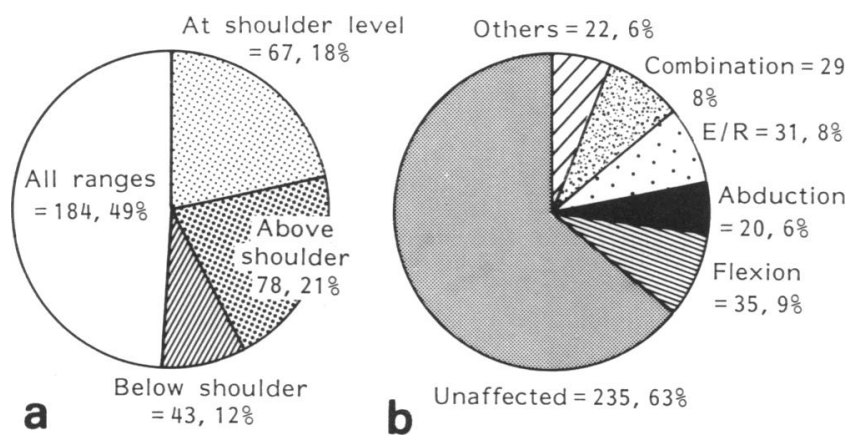

Figure 6. a: Movement with maximal effort and; b: painful movements $(\mathrm{N}=372)$

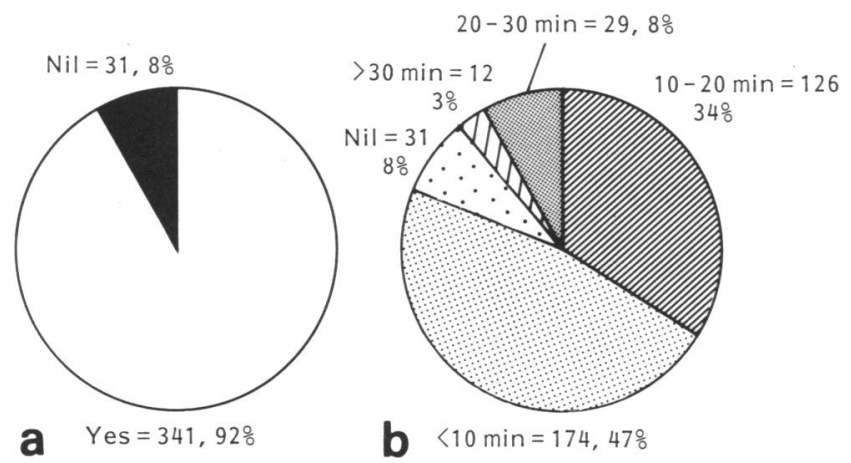

Figure 7. a: Availability of warming-up prior to acitivity and; b: duration $(\mathrm{N}=372)$

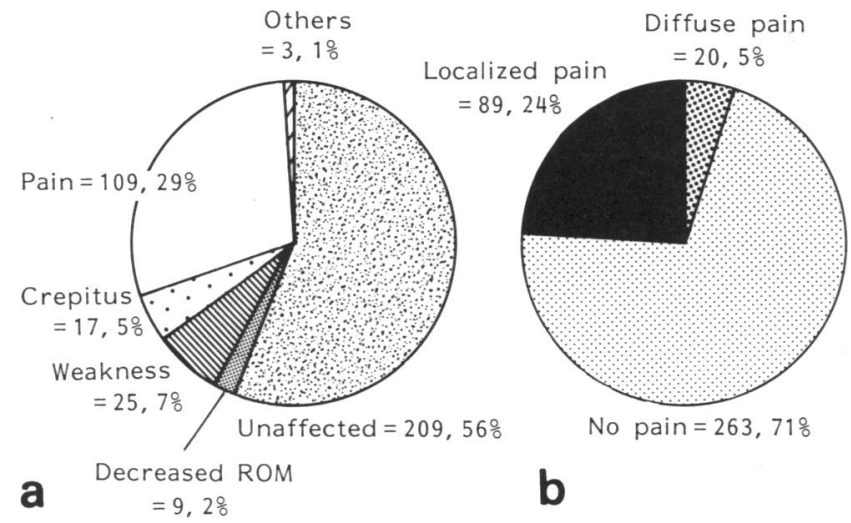

Figure 8. a: Major shoulder problem $(N=163)$ and; $b$ : nature of pain $(N=109)$
Table 3. Shoulder pain and miscellaneous shoulder problems among athletes of different events

\begin{tabular}{lccr}
\hline Sport & Pain & Other problems & Total \\
\hline Volley ball & $28(74 \%)$ & $10(26 \%)$ & 38 \\
Badminton & $10(52.6 \%)$ & $9(47.4 \%)$ & 19 \\
Basketball & $10(50 \%)$ & $10(50 \%)$ & 20 \\
Gymnastic & $4(80 \%)$ & $1(20 \%)$ & 5 \\
Squash & $6(66.7 \%)$ & $3(33.3 \%)$ & 9 \\
Swimming & $22(66.7 \%)$ & $11(33.3 \%)$ & 33 \\
Table tennis & $3(60 \%)$ & $2(40 \%)$ & 5 \\
Tennis & $10(90.9 \%)$ & $1(9.09 \%)$ & 11 \\
Field event & $3(37.5 \%)$ & $5(62.5 \%)$ & 8 \\
Others & $13(86.7 \%)$ & $2(13.3 \%)$ & 15 \\
Total & $109(66.87 \%)$ & $54(33.13 \%)$ & 163 \\
\hline
\end{tabular}

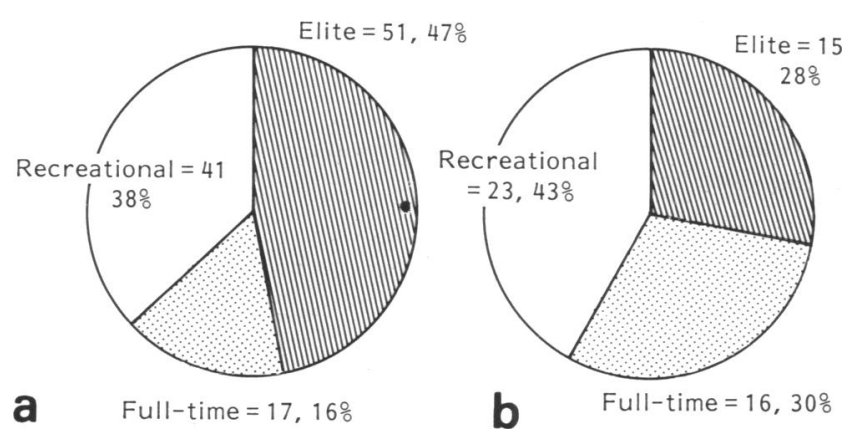

Figure 9. Shoulder problems among athletes from different sport backgrounds; a: athletes with shoulder pain; b: athletes with other shoulder problems

percent). While 64 athletes (17.2 percent) claimed throwing as their hardest movement, 42 respondents (11.3 percent) selected a combination of various upper arm movements (Figure $6 b$ ).

Of the 372 respondents, 31 (8.3 percent) did not do any warming-up exercises before activity. The 341 athletes (91.7 percent) who did warm-up, did so for various times illustrated in Figure 7.

The major concern of the study was to find out the incidence of shoulder pain during upper arm activities and whether any localized pain reported was due to supraspinatus tendinitis. Respondents identifying such symptoms would be further evaluated by a standardized assessment method for SIS.

It was found that 163 respondents (32.8 percent) had shoulder problems with the symptoms set out in Figure $8 a$, and the quality of their pain in Figure $8 b$.

Cross-tabulation revealed a high level of pain in respondents with shoulder symptoms which included crepitus, weakness and decreased movement ranges (Table 3).

The frequency of pain and other shoulder problems associated in different athletic groups is indicated in Figures 9-12.

10 1dentity the correlation between warming up exercise and the presence of shoulder problems, the data reflected that there were 13 subjects (42 percent) from the nil warming-up group $(\mathrm{N}=31)$ and 150 athletes (44 percent) from the warming-up group $(\mathrm{N}=341)$ with shoulder complaints (Figure 13). 
The incidence, frequency and type of previous injury are shown in Figures 14 and 15. Some respondents were not sure of the type of their previous injuries.

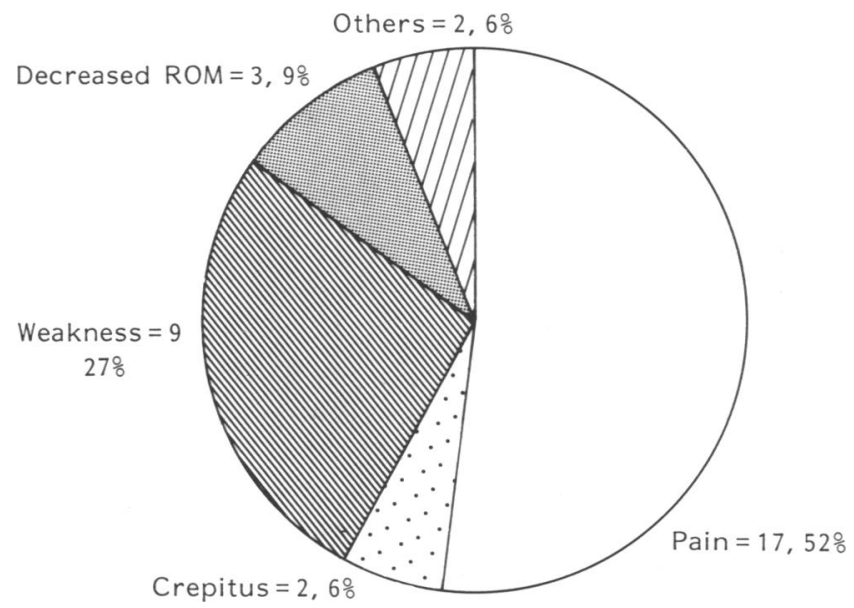

Figure 10. Nature of shoulder problem among full-time participants $(\mathrm{N}=33)$

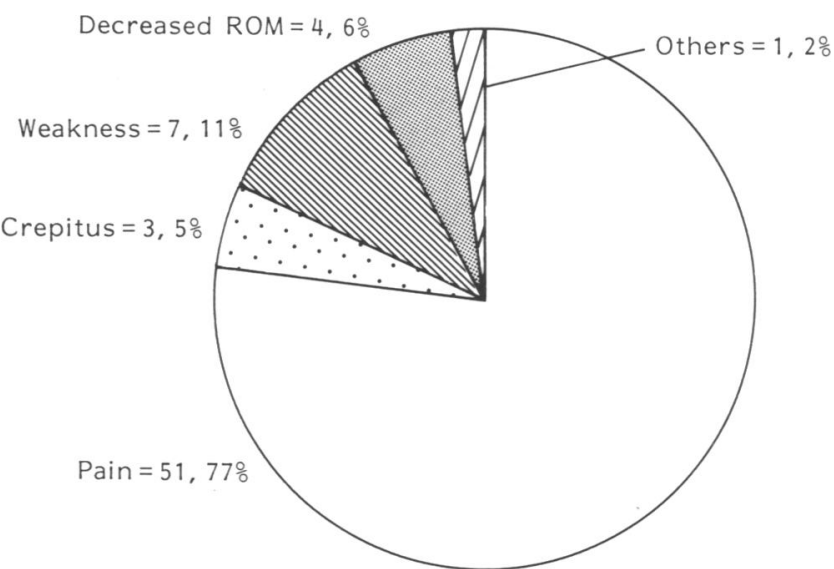

Figure 11. Nature of shoulder problem among elite athletes $(N=66)$

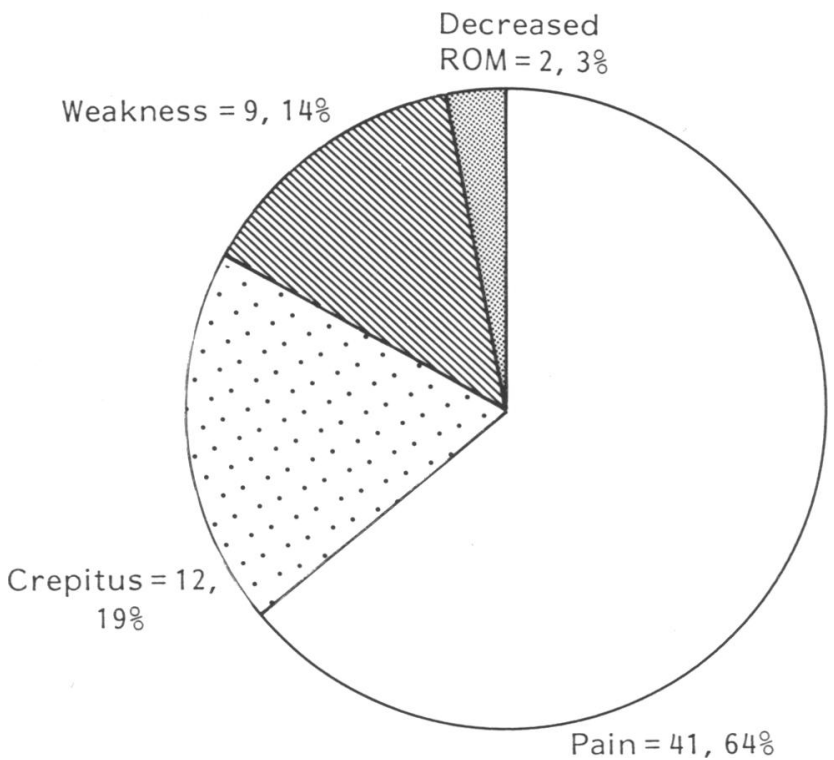

Figure 12. Nature of shoulder problem among recreational participants $(\mathrm{N}=64)$

\section{Discussion}

The prevalence of shoulder problems in upper arm sports was high $-\mathbf{4 3 . 8}$ percent of respondents - with pain as the main complaint followed by weakness and crepitation. Pain in the shoulder during movement was more pronounced in the elite group.

The predominance of male subjects reporting shoulder pain correlates with the findings of Backx et al. ${ }^{9}$, Collins et al. ${ }^{10}$ and Winge et al. ${ }^{8}$ who all commented that the choice of sport would be a significant determinant of rate and pattern of injury.

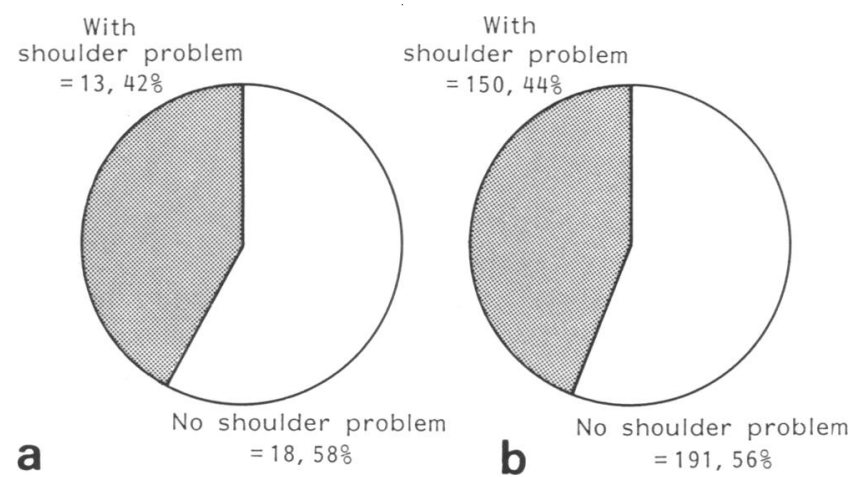

Figure 13. Correlation of warming-up activities with shoulder problems a: no warm-up $(\mathrm{N}=31)$; b: with warm-up $(N=341)$

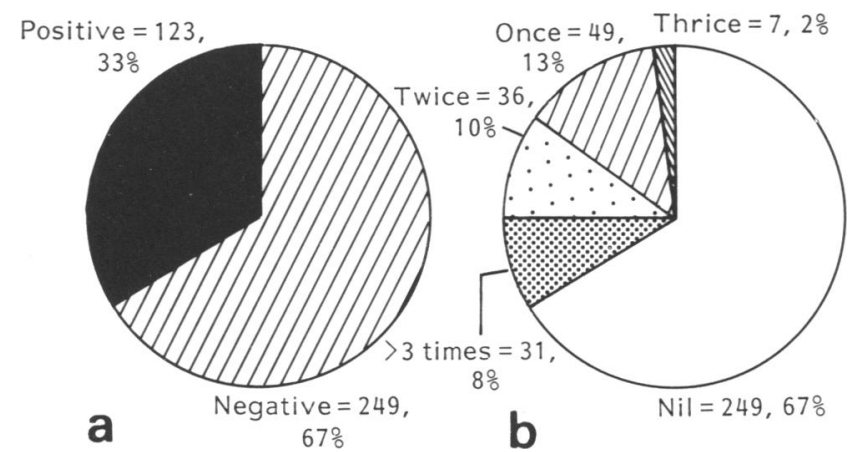

Figure 14. Previous shoulder injuries a: presence of previous shoulder injuries; b: episodes of previous shoulder injuries

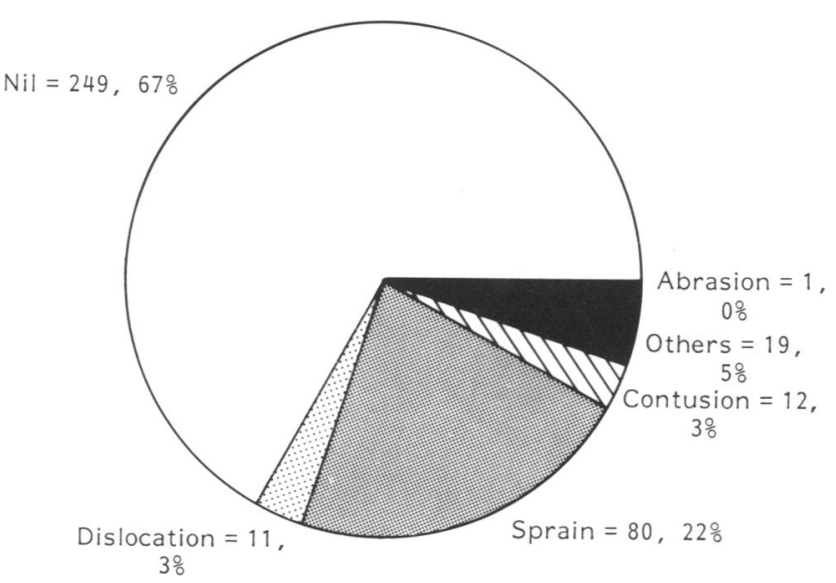

Figure 15. Nature of initial shoulder injury $(N=123)$ 
Hand dominance did contribute to the occurrence of shoulder symptoms, 106 respondents (28.5 percent) being affected on their dominant sides and only 22 (5.9 percent) on the non-dominant side.

Arm overuse leading to symptoms was described by Hawkins and Hobeika ${ }^{4}$ and DeBenedette ${ }^{5}$. The use of the dominant hand alone in racket sports and certain throwing events might exert maximal stress on the subacromial structures of the most active side.

Among the 123 respondents who had sustained previous shoulder injuries, the prevalence of shoulder pain (67.5 percent) was similar to that in the nil previous injury group (66.3 percent). The probability of sustaining further musculoskeletal shoulder problems was twice as high if there were previous shoulder injuries.

\section{Acknowledgements}

We are much indebted to Dr. M. K. Chin for providing subjects from his department at the Jubilee Sports Centre. Special thanks should also be given to Miss Josephine Yeung of the above centre and the physiotherapy students of the Hong Kong Polytechnic for supporting in the study.

Copies of the Shoulder Impingement Profile Study questionnaire are available on request from the authors.

\section{References}

1 Moseley, H.F. The vascular supply of the rotator cuff Surgical Clinics of North America 1963, 43, 1521-1522

2 Rothman, R.H. and Parke, W.W. The vascular anatomy of the rotator cuff Clinical Orthopaedics 1965, 41, 176-186

3 Hawkins, R.J. and Kennedy, J.C. Impingement syndrome in athletes American Journal of Sports Medicine 1980, 8(3), 151-158

4 Hawkins, R.J. and Hobeika, P.E. (1983) Impingement in the atheletic shoulder Clinics in Sports Medicine 1983, 2(2), 391-405

5 DeBenedette, V. Rotator cuff problems among top athletes The Physician and Sportsmedicine 1989, 17(5), 184-186

6 Chard, M.D. et al. The long-term outcome of rotator cuff tendinitis - a review study British Journal of Rheumatology 1988, 27, 385-389

7 Chinn, C.J. et al. Upper extremity range of motion, grip strength, and girth in highly skilled tennis players Physical Therapy 1974, 54, 474-483

8 Winge, S. et al. Epidemiology of injuries in Danish Champtionship Tennis Intnerational Journal of SPorts Medicine 1989, 10, 368-371

9 Backx, F.J.G. et al. Sports injuries in school-aged children: an epidemiologic study American Journal of SPorts Medicine 1989, 17(2), 234-240

10 Collins, K. et al. Overuse injuries in triathletes: a study of the 1986 Seafair Triathlon American Journal of Sports Medicine 1989, 17(5) 675-680 